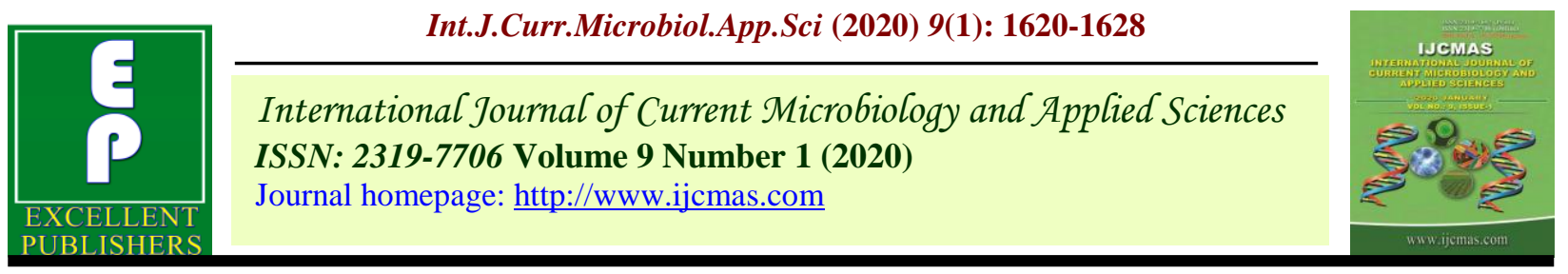

Original Research Article

https://doi.org/10.20546/ijcmas.2020.901.178

\title{
Effect of Terminal Heat Stress on Variability in Physiological Traits of Indian Mustard (Brassica juncea L.) due to Late Sown Situation
}

\author{
Sanjay Kumar Tripathi*, Lallu, Shubham Kumar Srivastava, \\ Vikas Yadav and Madhukar Singh \\ Department of Crop Physiology, Chandra Shekhar Azad University of Agriculture \& \\ Technology, Kanpur-208002 (U.P.) India \\ *Corresponding author
}

\begin{tabular}{l} 
Ke y w o r d s \\
Chlorophyll \\
Content, CSI, Net \\
Photosynthesis \\
Rate, CTD, RWC \\
and Seed Yield \\
\hline Article Info \\
\hline $\begin{array}{l}\text { Accepted: } \\
\text { 15 December } 2019 \\
\text { Available Online: } \\
\text { 20 January } 2020\end{array}$ \\
\hline
\end{tabular}

The investigation entitled "Effect of terminal heat stress on variability in physiological traits of Indian mustard (Brassica juncea L.) due to late sown situation" was conductedrabi season during 2017-18 and 2018-19 at Oil seed research Farm Kalyanpur of C. S. Azad University of Agriculture and Technology, Kanpur (U.P.) in randomized block design with three replications and twelve Indian mustard genotype. Physiological parameters i.e., Chlorophyll Content was recorded at anthesis and siliquae initiation stage; Chlorophyll Stability Index (CSI \%), Net Photosynthesis Rate $\left[(\mathrm{Pn})\left(\mu \mathrm{mol} / \mathrm{m}^{-2} / \mathrm{s}^{-}\right.\right.$ $\left.{ }^{1}\right)$ ], Relative Water Content (RWC \%)and Canopy Temperature Depression (CTD ${ }^{0} \mathrm{C}$ ) were estimated at pre-flowering and post-flowering stage.Study revealed that DRMRIJ16-3, RGN-403 and RH-1556 recorded higher CSI $(0.53,0.52$ and 0.46$)$, net photosynthesis rate (33.5, 33.0 and 32.6), Relative Water Content (60.8, 59.7 and 59.1) and canopy temperature depression $(3.5,3.7$ and 3.5$)$ at post-flowering stage, while higher chlorophyll content was recorded $(41.3,40.6$ and 39.2) at siliquae initiation stage. The study indicated that mustard genotypesDRMRIJ16-3, RGN-403 and RH-1556 had tolerance to high temperature stress with delayed sowing, as they maintained higher values of these physiological parameters.

\section{Introduction}

Mustard (Brassica juncea L. Czern \& Coss) is an important Rabiseason oilseed crop which belongs to family crucifereae (Brassicaceae) and genus Brassica. Indian mustard or brown mustard is natural amphidiploids having chromosome no. $(2 n=36)$ with its origin place is China. It is self-pollinated crop but certain amount $(2-15 \%)$ of cross pollination occurs due to insects and other factors. Mustard is cool season crop, which requires temperature range from 6 to $27^{\circ} \mathrm{C}$, mustard follows $\mathrm{C}_{3}$ pathway for carbon assimilation and at this temperature the plant achieve maximum $\mathrm{CO}_{2}$ assimilation range. Mustard is generally grown under rain fed conditions and moderately tolerant to soil acidity. It requires well drained soil having $\mathrm{pH}$ near to neutral. Mustard has a low water requirement (240$400 \mathrm{~mm}$ ) which fits well in the rain fed cropping system. Nearly $20 \%$ area of mustard is under rain fed condition. Its seeds are known by different names in different places 
e.g., sarson, rai or raya, toria or lahi. White sarson and toria are termed as rape seed, rai or raya or laha is termed as mustard. Oil content in seeds varies from 37 to 49 per cent. The oil obtained is the main cooking medium in northern India and cannot be easily replaced by any other edible oil. The seed and oil of mustard have a peculiar pungency due to presence of glucosinolate and its hydrolysis products such as allyl isothiocynate $(0.30$ $0.35 \%$ ) making it suitable to use as condiment in the preparation of pickles and for flavouring curries and vegetables. The oil cake is used as a cattle feed and manure. The leaves of young plants are used as green vegetables as they supply enough sulphur and minerals in the diet.

Indian mustard is sown late due to delay in harvesting of rainy season crops like cluster bean, cotton and rice (Kumar et al., 2013). Under late sown condition, productivity declines primarily due to the shortening of vegetative and reproductive phase. Late sown Indian mustard is exposed to high temperature coupled with high evaporative demand of the atmosphere, during the reproductive phase which consequently results in forced maturity, increased senescence and low productivity (Porter, 2005). Delay planting has been observed to have adverse effect on seed yield. In our country mustard is grown as a winter crop. The rise in temperature, even by a single degree beyond the threshold level is considered as heat stress in the plants (Hasanuzzaman et al., 2013 and Wahid et al., 2007). Climate change has increased the intensity of heat stress and heat stress due to increased temperature is an agricultural problem in many areas in the world as well as in India (Beck et al., 2007).Constantly high temperatures cause an array of morphological, physiological and biochemical changes in plants (Serraj et al., 1999 and Moradshahiet al.,2004).

Heat stress has significant negative effect on the leaf chlorophyll content however, the reduction is time dependent. Reduction in total chlorophyll content is related with photosynthesis reduction as a result of reduce antenna size and thus less light harvesting during heat stress (Al-Khatib and Paulsen, 1984; Blum, 1986; harding et al., 1990; Shanmugam et al., 2013).High temperature damage photosynthetic membrane and resulted in chlorophyll loss (Al-Khatib and Paulsen, 1984). The terminal heat stress at pre-flowering and post-flowering stage accelerate maturity and significantly reduce CSI, CTD, RWC, photosynthetic rate and ultimately reduce grain yield. Indian mustard for different physiological parameters viz., chlorophyll content, membrane stability index (MSI\%), relative water content (RWC\%) and electrolyte leakage and yield related to terminal heat tolerance (Kavita and Pandey 2018).Therefore, present study was conducted effect of terminal heat stress on variability in physiological traits of Indian mustard due to exposure late sowning elevated temperature.

\section{Materials and Methods}

The field experiment was conducted at Oil seed research Farm Kalyanpur of C. S. Azad University of Agriculture and Technology, Kanpur, (U.P.) India. This farm is situated about $3 \mathrm{~km}$ away from main campus of university on South side of G.T. road runs towards Delhi.The experimental place Kanpur is situated at latitude of $26^{\circ} 28^{-}$North and longitude of $80^{\circ}$ 24 East, on altitude of 129 meter about mean sea level. It has semisubtropical climate. The average annual rainfall of the region is $762 \mathrm{~mm}$ and most of it is received since last week of June to middle of October month andsome occasional showers are also received during winter months. The experimental site was having sandy loam soil with $\mathrm{pH} 7.7$, organic carbon $0.41 \%$, available nitrogen $183.4 \mathrm{~kg} / \mathrm{ha}$, available phosphorous $18.3 \mathrm{~kg} / \mathrm{ha}$, and available potassium $248.2 \mathrm{~kg} / \mathrm{ha}$.Soil moisture content i.e. water holding capacity $(33.5 \%)$, 
Field Capacity (19.2\%) in soil at sowing time of crop was sufficient for proper germination of crop seeds. The experiments were laid out in a randomized block design with three replications. Twelve mustard genotype viz., Vardan, Ashirwad, NPJ-207, NPJ-208, RGN403, PBR-417, DRMRIJ 16-3, DRMR-2035, RRN-911, RH-1556, RGN-368 and BPR 5414 were sown under late sown condition during 2017-18 and 2018-19.

CSI, Net Photosynthesis Rate, CTD and RWC were estimated viz., at pre-flowering and post-flowering stage, while Chlorophyll Content measured at anthesis and siliquae initiation stage. Chlorophyll Content (SPAD) was recorded by a hand-held device chlorophyll model: SPAD-502 PLUS (company MANTOLA), Rate of Photosynthesis $\left(\mu \mathrm{mol} / \mathrm{m}^{-2} / \mathrm{s}^{-1}\right)$ was measured using CI-301 $\mathrm{CO}_{2}$ Gas analyzer CID, Inc. Chlorophyll Stability Index (\%) Green plant pigments are thermo sensitive and its degradation occurs when it is subjected to higher temperature. It was estimated at given below procedure.

Two clean glass tubes were taken and $5 \mathrm{mg}$ of representative leaf sample was placed in each tube with $50 \mathrm{ml}$ of distilled water. One tube was subjected to heat in water bath at $56{ }^{0} \mathrm{C} \pm$ $1{ }^{0} \mathrm{C}$ for exactly 30 minutes. Other tube was kept as control. The leaves are then ground in mortar for 5 minutes with $100 \mathrm{ml}$ of $80 \%$ acetone. The slurry was filtered with Whatman no. 1 filter paper. This chlorophyll extract was further examined immediately for light absorption with photoelectric colorimeter using red filter (No. 66). A parallel leaf sample of $250 \mathrm{mg}$ in another tube was then estimated for chlorophyll content without heating simultaneously and light absorption was measured with colorimeter as explained.

CSI $(\%)=($ Chlorophyll in the stressed plant leaf / Chlorophyll in control plant Leaf) $\times 100$
Canopy temperature depression (CTD) ${ }^{0} \mathrm{C}$ was measured were made by using a handy Infra-red Thermometer (Tele-temp AG-42 USA).

a) The difference between ambient and canopy temperature has to be entered in the data book.

b) Canopy in the area earmarked for final observation may be focused for Canopy temperature Depression measurement.

c) Care should be taken to see that angle and the distance between the canopy and the Infra red thermos-meter remain constant for each plant.

d) Observation should be recorded between 10:00 to 13:00 hours (mid day).

Relative water content (\%) of third leaf from top of the main shoot was estimated as per method Suggested by Weatherley and Slatyer (1970) as follows-

RWC $(\%)=($ Fresh weight - oven dried weight) / (Turgid weight - oven dried weight) $\times 100$

\section{Results and Discussion}

Chlorophyll SPAD value in leaf tissue was recorded more at anthesis than siliquae initiation stage showed significant differences among tested mustard genotypes under late sown situation (Table 1). Chlorophyll content in the different mustard genotypes varied significantly from 38.6 to 45.9 at anthesis stage and from 32.2 to 41.3 at siliquaeinitiation stage. The data pooled over the years (Table-1) indicated that mustard genotypes DRMRIJ 16-3 (45.9) followed by NPJ-208 (45.7), RGN-403 (45.5) and Vardan (44.7) at anthesis stage and DRMRIJ 16-3 (41.3) followed by RGN-403 (40.6) and RH1556 (39.2) at siliquae initiation stage identified as superior genotypes under given situation as these maintained higher chlorophyll content (SPAD value) in leaf 
tissue as compared to other genotypes. Genotype PBR-417 (38.6) and RGN-368 (39.4) at anthesis, RRN-911 (32.2) and RGN368 (32.8) at siliquae initiation proved poor performer under late sown situation as these gave significantly lowest value of SPAD in leaf.Similar to our finding Jangid and Srivastava (2018) was also suggested anthesis stage chlorophyll content in flag leaf decreased in plant January 10 and 25 December as compared to 26 November.

Chlorophyll stability index (CSI \%) was estimated at pre-flowering and post-flowering stage are presented in Table-1.In general the value of CSI was higher at pre-flowering than post-flowering stage in all tested genotypes of mustard during both years of experimentation. Chlorophyll stability index in the different mustard genotypes varied significantly from 0.52 to 0.64 at pre-flowering stage and from 0.37 to 0.53 at post-flowering stage. Result based on pooled analysis over two years data revealed that mustard genotypes RGN-368 (0.64) and RRN-911 (0.63) remained statistically at par at pre-flowering and genotypes DRMRIJ 16-3 (0.53) and RGN403 (0.52) at post-flowering maintained significantly higher value of CSI (\%) and proved their superiority over other genotypes grown in late sown situation. The significantly lowest value of CSI (\%) was exhibited in PBR-417, BPR 541-4 (0.52) and Vardan (0.53) at pre flowering and NPJ207(0.37) and BPR 541-4 (0.38) at post flowering which showed that these genotypes indicates its greater susceptibility to heat stress at terminal stage. The varietal differences in CSI, among the genotypes in the present study seems to be associated with the ability of different genotypes to reduced more destruction of CSI under high temperature at seed filling stage under late sown condition. Dogra et al., (2018) revealed that heat stress decreased Chlorophyll Stability Index.
Rate of photosynthesis $(\mathrm{Pn})\left(\mu \mathrm{mol} / \mathrm{m}^{-2} / \mathrm{s}^{-1}\right)$ of all twelve promising mustard genotypes was noted more at post-flowering than preflowering stage during both years of experimentation. Pooled analysis of both years data showed that mustard genotypes DRMRIJ 16-3 (27.1) followed by NPJ-208 (26.5) and RGN-403 (26.4) at pre-flowering and DRMRIJ 16-3 (33.5) followed by RGN403 (33.0) and RH-1556 (32.6) at postflowering performed better as these maintained significantly higher rate of photosynthesis $\left(\mu \mathrm{mol} / \mathrm{m}^{-2} / \mathrm{s}^{-1}\right)$ under late sown environment over the other genotypes of mustard tested. Genotypes RGN-368 (24.3) and BPR 541-4 (24.4) at pre-flowering and RRN-911 (29.3) and RGN-368 (29.8) at postflowering appeared poor performer under given situation as these showed significantly lower value of Net Photosynthetic Rate $(\mu$ $\mathrm{mol} / \mathrm{m}^{-2} / \mathrm{s}^{-1}$ ) than other genotypes.

The varietal variation in net photosynthesis among the genotypes in the present study seems to be associated with the ability of different genotypes due to their genetic potential with heat tolerance through higher leaf area might has utilized more solar radiation and enhanced the photosynthesis activity in plants. Our findings are in agreement with the earlier studies on Indian mustard by Cmejo et al., (2005) and Singh et al., (2014). Canopy Temperature Depression $\left(\mathrm{CTD}^{0} \mathrm{C}\right)$ of 12 promising mustard genotypes at pre flowering and post flowering are presented in Table 2.

Mustard genotypes RGN-403 (3.7), RH-1556 (3.5) and DRMRIJ 16-3 (3.5) exhibited higher value of CTD difference at both pre and post flowering stages, while the lowest value of CTD was observed in PBR-417 (2.9) and RGN-368 (2.9) at pre flowering and RRN-911 (2.4), PBR-417 (2.5) at post flowering under late sowing stress based on pooled analysis of both years data.Similar results were founded by Gill (2007). 
Table.1 Chlorophyll content, Chlorophyll Stability Index and Net photosynthesis rate at different growth stages in Indian mustard under late sown condition (pooled 2 years)

\begin{tabular}{|c|c|c|c|c|c|c|}
\hline \multirow[t]{2}{*}{ Genotypes } & \multicolumn{2}{|c|}{ Chlorophyll content (SPAD) } & \multicolumn{2}{|c|}{$\begin{array}{c}\text { Chlorophyll Stability Index } \\
\text { (CSI) (\%) }\end{array}$} & \multicolumn{2}{|c|}{$\begin{array}{l}\text { Net photosynthesis rate }(\operatorname{Pn})(\mu \\
\left.\mathrm{mol} / \mathrm{m}^{-2} / \mathrm{s}^{-1}\right)\end{array}$} \\
\hline & Anthesis & $\begin{array}{l}\text { Siliquae- } \\
\text { initiation }\end{array}$ & $\begin{array}{c}\text { Pre- } \\
\text { flowering }\end{array}$ & $\begin{array}{c}\text { Post- } \\
\text { flowering }\end{array}$ & $\begin{array}{c}\text { Pre- } \\
\text { flowering }\end{array}$ & $\begin{array}{c}\text { Post- } \\
\text { flowering }\end{array}$ \\
\hline Ashirwad & 42.6 & 34.8 & 0.54 & 0.39 & 24.6 & 31.3 \\
\hline NPJ-207 & 40.3 & 35.7 & 0.58 & 0.37 & 25.2 & 31.3 \\
\hline NPJ-208 & 45.7 & 38.6 & 0.59 & 0.41 & 26.5 & 32.1 \\
\hline PBR-417 & 38.6 & 33.7 & 0.52 & 0.43 & 25.1 & 31.1 \\
\hline DRMRIJ 16-3 & 45.9 & 41.3 & 0.54 & 0.53 & 27.1 & 33.5 \\
\hline DRMR-2035 & 44.1 & 37.2 & 0.55 & 0.41 & 25.3 & 32.3 \\
\hline RRN-911 & 41.5 & 32.2 & 0.63 & 0.39 & 25.1 & 29.3 \\
\hline RH-1556 & 44.6 & 39.2 & 0.61 & 0.46 & 25.7 & 32.6 \\
\hline RGN-368 & 39.4 & 32.8 & 0.64 & 0.41 & 24.3 & 29.8 \\
\hline C.D.5\% & 1.94 & 1.57 & 0.02 & 0.45 & 0.89 & 1.40 \\
\hline
\end{tabular}


Table.2 Canopy Temperature Depression, Relative Water Content, Membrane Injury Index and seed yield at different growth stages in Indian mustard under late sown condition (pooled 2 years)

\begin{tabular}{|c|c|c|c|c|c|}
\hline \multirow[t]{2}{*}{ Genotypes } & \multicolumn{2}{|c|}{$\begin{array}{c}\text { Canopy Temperature Depression } \\
\left.\text { (CTD }{ }^{0} \mathrm{C}\right)\end{array}$} & \multicolumn{2}{|c|}{ Relative Water Content (\%) } & \multirow[t]{2}{*}{$\begin{array}{l}\text { Seed Yield }(g \\
\left.\text { plant }^{-1}\right)\end{array}$} \\
\hline & Pre-flowering & Post-flowering & Pre-flowering & Post-flowering & \\
\hline Vardan & 3.9 & 3.2 & 78.9 & 57.6 & 16.5 \\
\hline Ashirwad & 3.3 & 3.1 & 77.0 & 55.7 & 15.4 \\
\hline NPJ-207 & 3.8 & 3.0 & 76.8 & 55.9 & 15.5 \\
\hline NPJ-208 & 3.8 & 3.4 & 78.8 & 58.4 & 16.8 \\
\hline RGN-403 & 4.3 & 3.7 & 79.5 & 59.7 & 17.7 \\
\hline PBR-417 & 2.9 & 2.5 & 76.7 & 54.8 & 13.5 \\
\hline DRMRIJ 16-3 & 4.0 & 3.5 & 79.6 & 60.8 & 18.5 \\
\hline DRMR-2035 & 3.5 & 3.1 & 78.5 & 57.1 & 16.5 \\
\hline RRN-911 & 3.4 & 2.4 & 76.8 & 54.9 & 12.6 \\
\hline RH-1556 & 4.2 & 3.5 & 78.9 & 59.1 & 17.5 \\
\hline RGN-368 & 2.9 & 2.6 & 76.0 & 54.6 & 13.1 \\
\hline BPR 541-4 & 4.1 & 2.8 & 76.7 & 54.6 & 14.3 \\
\hline Mean & 3.6 & 3.1 & 77.8 & 56.9 & 15.7 \\
\hline S.E.(d) & 0.21 & 0.13 & 0.86 & 1.05 & 0.66 \\
\hline C.D.5\% & 0.43 & 0.26 & 1.74 & 2.11 & 1.34 \\
\hline
\end{tabular}


Relative water content (RWC\%) as influenced by late sowing estimated at pre flowering and post flowering stages are given in Table 2 clearly revealed that it varied significantly due to genotypes under late sown condition during both years of study i.e., 2017-18 and 2018-19. The pooled data analysis over the two years at pre flowering stage revealed that genotypes DRMRIJ 16-3 (79.6) being at par with RGN-403 (79.5), Vardan (78.9) and RH1556 (78.9) proved its superiority as these maintain significantly higher relative water content in their leaves over other genotypes, while the lowest value of RWC were recorded in genotypes RRN-911 (38.2) and RGN-368 (38.3). At post flowering also again genotypes RH-1556 (63.0), RGN-403 (62.0) and DRMRIJ 16-3 (61.5) maintain higher status of RWC over the other genotypes, while lowest value of it at this stage was recorded in PBR417 (56.5) and Ashirwad (56.6) under late sown environment. Our present findings are in agreement with the Indian mustard Ram et al., (2014) and Sudhir et al., (2013) and also similar results due to late sown has also been reported in the literature Sairam et al., (2002); Kumar et al., (2013); Kavita and Pandey (2018) in mustard crop.

Seed yield (g plant ${ }^{-1}$ ) recorded at harvest (Table 2) showed significant genotypic variation among 12 genotypes under late sown condition analysis of both years data resulted that the genotypes, DRMRIJ 16-3 (18.5) followed by RGN-403 (17.7) and RH1556 (17.5) were found significantly superior in seed yield indicating that these were suitable genotypes for late sowing environments with higher seed yield potential over the others genotypes. Genotypes RRN911 (12.6) followed by RGN-368 (13.1) were unable to perform better under late sown condition as these exhibited significantly lowest seed yield over rest of the genotypes should be avoided for late sowing. Similar reduction in seed yield and genotypic differences in late sown brassica crops were observed by Lallu et al., (2010); Gawariya et al., (2015); Hasan et al., (2016) and Singh et al., (2017).

\section{References}

Al-Khatib, K. and Paulsen, G.M. (1984). Mode of high-temperature injury to wheat during grain development. Plant Phy., 61: 363-368.

Beck, E. H., Fettig, S., Knake, C., Hartig, K., and Bhattarai, T. (2007). Specific and unspecific responses of plants to cold and drought stress. Journal of Biosciences, 32: 501-510.

Blum, A. (1986). The effect of heat stresses on wheat leaf and ear photosynthesis. $J$. Exp. Bot., 37: 111-118.

Camejo, D., Rodriguez, P., Moreles, M. A., Amico, J. M., Torrecillas, A. and Alarcon, J. J. (2005). High temperature effects on photosysnthetic activity of two tomato cultivars with different heat susceptibility. Journalof Plant Physiology, 162: 281-289.

Dogra,Sapalika. Chand., Gurdev and Sinha, B.K. (2018). Physiological and biochemical traits as tools to screen sensitive and resistant genotypes of Brassica juncea exposed to drought stress, Journal of Pharmacognosy and Phytochemistry, 7(5): 877-884.

Gawariya, S.C., Chopra, N.K., Chopra, N. and Harika, A.S. (2015). Effect of date of sowing and crop geometry on growth and yield parameters of forage mustard (Var. Chinese Cabbage). African Journal of Agricultural Research, 10 (33): 3292-3295.

Gill, K. K. and Bains, G.S. (2007). Seed yield and prediction of Brassica carinata from canopy temperayure based indices. Indian J Eco., 33: 144-146.

Harding, S. A., Guikema, G. A. and Paulsen, G. M. (1990). Photosynthetic decline 
from high temperature stress during maturation of wheat. II Interaction with source and sink processes. Plant Physiology, 92: 654-658.

Hasan, Ejaz-ul, Mustafa, Hafiz Saad Bin. Hassan, Mariam. Mahmood, Tariq. and Salah-ud-Din, Sultan (2016). Correlation and path coefficient studies in elite lines of rapeseed (Brassica napus L.) J. Agric. Basic Sci., 01, 02,

Hasanuzzaman, M., Nahar, K., Alam, M. M., Roychowdhury, R. and Fujita, M. (2013). Physiological, biochemical, and molecular mechanisms of heat stress tolerance in plants. InternationalJournal of Molecular Sciences, 14: 9643-9684.

Jangid Krishna Kumar and Srivastava Jai Prakash (2018). Canopy Temperature Depression and Stay Green: Major Components for Identifying Terminal Heat Stress Resistant Genotypes of Wheat. Int. J. Pure App., 6 (3): 374-381 (2018).

Kavita and Pandey, Anil (2018). Physiological Attributes for Screening of Indian mustard (Brassica juncea L. Czern and Coss) Genotypes during Terminal Heat Stress Int.J.Curr.Microbiol.App.Sci.,6 (9): 2908-2913.

Kumar, S., Sairam, R. K. and Prabhu, K. V. (2013). Physiological traits for high temperature stress tolerance in Brassica juncea. Indian Journal of Plant Physiology. 18: 89-93.

Lallu, Baghel, R. and Srivatava, S.B.L. (2010). Assessment of Mustard genotypes for thermo-tolerance at seed development stage.Indian $J$ of Plant physiology, 15 (1), 36-43.

Moradshahi, A., Eskandari, B.S. and Kholdebarin, B. (2004). Some physiological responses of canola (Brassica napus L.). Iranian Journal of Sccience and Technology, 28:43-50.

Porter, J. R. (2005). Rising temperatures are likely to reduce crop yields. Nature, 436: 174.

Ray, J. and Ahmed, J. U. (2015). Canopy Temperature Effects on Yield and Grain growth of Different Wheat Genotypes, IOSR Journal of Agriculture and Veterinary Science, 2319-2372.8, 7 ,PP 48-55.

Sangwan, Sunita, Ram Kirpa, Rani, Pooja and Munjal, Renu (2018). Effect of Terminal High Temperature on Chlorophyll Content and Normalized Difference Vegetation Index in Recombinant Inbred Lines of Bread Wheat. Int.J.Curr.Microbiol.App.Sci., 7 (6): 1174-1183.

Serraj, R., Sinclair, T.R. and Purcell, L.C. (1999). Symbiotic N2 fixation response to drought. Journal of Experimental Botany,50: 143-155.

Shanmugam, S., Kjaer, K.H., Ottosen, C.O., Rosenqvist, E., Kumari, S. and Wollenweber B. (2013). The alleviating effect of elevated $\mathrm{CO} 2$ on heat stress susceptibility of two wheat (Triticumaestivum L.) cultivars. J. Agron Crop Sci., 199: 340-50.

Sharma, Devender, Jaiswal, J.P., Singh, N.K., Chauhan, Anjana and Gahtyari, Navin Chander (2018). Developing a Selection Criterion for Terminal Heat Tolerance in Bread Wheat Based on Various Mopho-Physiological Traits. Int.J.Curr.Microbiol.App.Sci.,7 (7) : 2716-2726.

Singh, Baldeep., Thakral, N.K., Munjal, Renu and Boken, Geeta (2017). Combining Ability Analysis: Physiological Traits for High Temperature Stress Tolerance in Indian Mustard [Brassica juncea (L.) Czern \& Coss.] Int J. Pure App. Biosci., 5 (5): 725-735.

Singh, N.B., Singh, Y.P. and Singh, V.P.N. (2005). Variation in physiological traits in promising Wheat varieties under late sowing condition. India J. Plant 
physioogy, 10 (2): 171-175.

Singh, V.V., Ram, B., Singh, M., Meena, M.L. and Chauhan, J.S. (2014). Generation mean analysis forwater stress tolerance parameters in Indian mustard [B. juncea (L.) Czern \& Coss] crosses.SABRAO Journal of Breeding Genetics, 46: 76-80.

Sudhir, K., Sairam, R.K. and Prabhu, K.V.
(2013). Physiological traits for high temperature stresstolerance in Brassica juncea. Indian Journal of Plant Physiology, 18: 89-93.

Wahid, A., and Close, T.J. (2007). Expression of dehydrins under heat stress and their relationship with water relations of sugarcane leaves. Biologia Plantarum, 51: 104-109.

\section{How to cite this article:}

Sanjay Kumar Tripathi, Lallu, Shubham Kumar Srivastava, Vikas Yadav and Madhukar Singh. 2020. Effect of terminal heat stress on variability in physiological traits of Indian mustard (Brassica juncea L.) due to late sown situation. Int.J.Curr.Microbiol.App.Sci. 9(01): 1620-1628 doi: https://doi.org/10.20546/ijcmas.2020.901.178 